\title{
Presence of Asian House Gecko Hemidactylus frenatus across an urban gradient in Brisbane: influence of habitat and potential for impact on native gecko species
}

\author{
Brock Newbery' and Darryl N. Jones ${ }^{1,2}$
}

'Suburban Wildlife Research Group, Australian School of Environmental Studies, Griffith University, Nathan, QId. 4II I, Australia.

${ }^{2}$ Corresponding author: Darryl Jones, D.Jones@griffith.edu.au

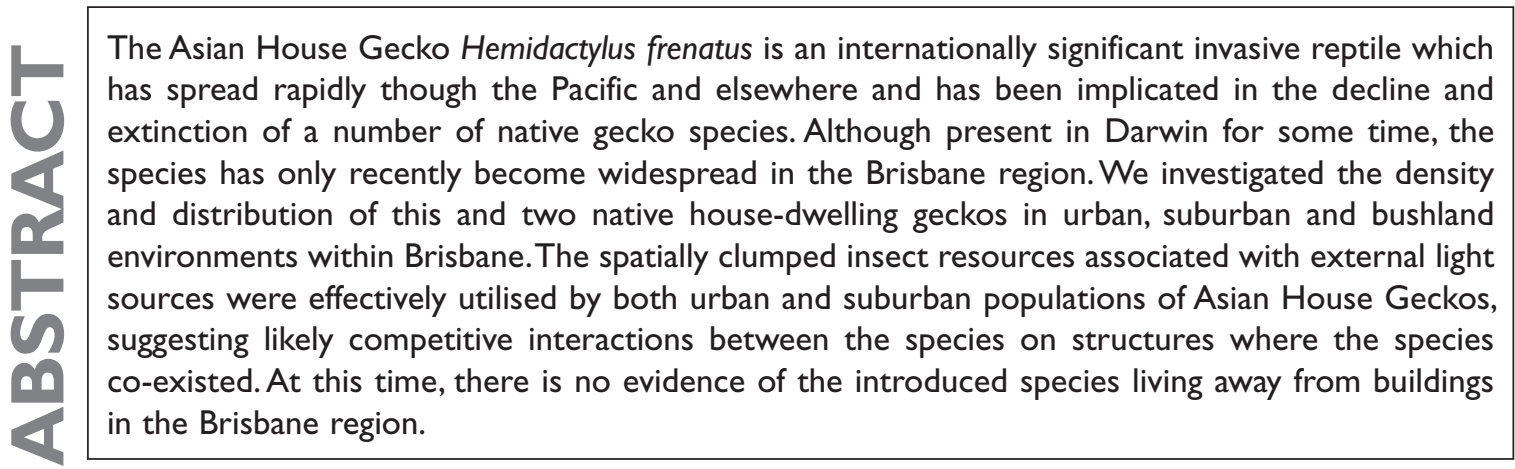

Key words: Asian House Gecko, invasive species, urban ecology

\section{Introduction}

Native to Asia and the Indo-pacific, the Asian House Gecko Hemidactylus frenatus is rapidly becoming a cosmopolitan species (Worthington-Wilmer et al. 2003, Vences et al. 2004) with a distribution closely associated with human habitation (Greer 1989). In the last 60 years it has successfully colonised island habitats throughout the Pacific region and the Americas, where it has been implicated in the decline and extinction of numerous other gecko species (Case et al. 1994, Hanley et al. 1998, Brown et al. 2002, Worthington-Wilmer et al. 2003, Cole et al. 2005).

The Asian House Gecko is highly synanthropic, regularly colonising human settlements and foraging on insects attracted to external lights. It is thought that the species' global distribution has increased since about the 1950s due to increases in international shipping and cargo movement (Greer 1989). Microscopic setae on the sub-digital lamellae increase the climbing ability of the species (Russell 2002, Pianka and Sweet 2005), allowing it to move and forage freely on the large, structurally simple, vertical and inverted surfaces (such as walls and windows) often illuminated by external light sources. This superior clinging ability also affords the species access to high crevice spaces for egg deposition and refuge from predators. These characteristics increase its potential to pass undetected in transit on shipping containers and cargo. Furthermore, the female's capacity for functional sperm retention facilitates successful establishment upon introduction to an new location due to a reduced necessity for mate acquisition (Murphy-Walker and Haley 1996).

During the Asian House Geckos numerous colonisation events, it has shown a propensity for competitive displacement of other human-associated geckos (Greer 1989, Case et al. 1994, Petren and Case 1996, Brown et al. 2002, Cole et al. 2005). Perhaps the most studied interaction is that which occurs between the Asian House Gecko and the Mourning Gecko Lepidodactylus lugubris on islands throughout the Pacific (Case et al. 1994). Many forms of competition have been experimentally demonstrated to exist between these species. Behavioural dominance is evidenced by the exclusion of the Mourning Gecko from concentrated food resources found around electric lights. This dominance is not displayed as overt interspecific aggression, but rather, by an avoidance response resulting in the Mourning Gecko occupying less favourable foraging positions (Petren et al. 1993). The reduced resource acquisition in the Mourning Gecko translates into a reduction in body condition, fecundity and survivorship (Case et al. 1994, Petren and Case 1996). Significantly, in the absence of Asian House Geckos, Mourning Geckos on some Pacific islands were eight times more abundant on buildings than on neighbouring islands where the two species were present together (Case et al. 1994).

In Australia, Asian House Geckos were first recorded in 1845 at the now abandoned settlement of Port Essington in the Northern Territory (Greer 2004). Thereafter the species apparently went unrecorded until the 1960s when a population was discovered in suburban Darwin (Swanson 1990). The first record in Brisbane was made in 1983, when customs and quarantine staff observed an apparently breeding population around the Brisbane wharves (Covacevich 2001). After an initial period of patchy distribution limited to suburbs adjacent to the Brisbane Port, the species expanded dramatically during the 1990s and is now the most frequently observed house- 
dwelling gecko in Brisbane (Newbery et al. 2005). It is also widely distributed through coastal regions of Queensland (Wilson and Swan 2003).

Studies of the invasive nature of the Asian House Gecko and potential competitive impacts on native geckos in Australia have only recently been undertaken. Keim (2002) compared the responses of Asian House Gecko populations to habitat edges on suburban and bushland sites in Brisbane and Darwin (Darwin's Asian House Gecko population being at least 20 years older than Brisbane's). Although it is often suggested that Asian House Geckos are confined to anthropogenic habitats, in Darwin Keim (2002) found 'significant densities' of Asian House Geckos up to $150 \mathrm{~m}$ into bushland. In contrast, Brisbane's Asian House Geckos tended to be at lower numbers on houses approaching suburban bushland reserves and to be absent within bushland itself. During her Brisbane surveys, Keim (2002) also recorded the Asian House Gecko, Dubious Dtella Gehyra dubia and Robust Velvet Gecko Oedura robusta present together on suburban sites when in close proximity to bushland.

Information on the density and distributions of Australian populations of the Asian House Gecko remains fragmentary. A preliminary investigation in Brisbane (Newbery et al. 2005) showed that significantly greater numbers were present on residential dwellings within the highly urbanised inner city suburbs compared to houses in the less structurally dense outer suburbs. Keim (2002) suggested that the densities of Brisbane's population may be restricted due a comparatively cooler climate than Darwin and / or due to the negative effects of interactions with native arboreal geckos.

The invasive nature of the Asian House Gecko in human habitats throughout the warmer regions of the world is now well recognised (Greer 1989, Meshaka et al. 1994, Petren and Case 1996, Hanley et al. 1998, Vences et al. 2004). This species is undergoing an ever-expanding distribution driven largely by human movements and alterations of natural habitats. It has been shown that when in competition with other native geckos occupying the house niche, the Asian House Gecko's superior foraging capabilities and ability to tolerate interspecific cohabitation better than many species, leads to a competitive advantage over, and often displacement of, the other species (Case et al. 1994, Brown et al. 2002, Cole et al. 2005). With this in mind, we investigated density and distribution and dietary characteristics of the Asian House Geckos and the two native species Dubious Dtellas and Robust Velvet Geckos occupying the same anthropogenic niche in urban, suburban, rural and bushland habitats in Greater Brisbane.

\section{Methods}

\section{Gecko presence and distribution}

Urban, suburban, rural and bushland habitats are dispersed throughout the Greater Brisbane region, forming a 'gradient' from the highly disturbed inner-city urban zone, through the suburbs to the rural and bushland areas beyond (McDonnell and Pickett 1990). Sixty-five sites (most represented by an individual single-storey dwelling) were selected from these four habitat types. Due to a limited number of bushland areas containing structures similar in size to a residential dwelling, only three bushlands were surveyed.

Sites were located in the following locations or Brisbane suburbs: Urban (Logan Central, Auchenflower, Spring Hill, Newstead); Suburban (Carole Park, Wynnum, Tarragindi, Easton's Hills); Rural (Carbrook, Waterford West, Pallara, Closeburn); and bushland (Brisbane Forest Park, Karawatha, Daisy Hill).

Sites were visited during the warmer months of JanuaryApril; geckos remained active throughout this period in Brisbane. The number of all house-dwelling geckos found at each site was determined using auditory and visual sampling techniques. The external surfaces of each structure (walls, eves, verandas, foundations etc, but excluding under-houses where applicable) were systematically searched for evidence of geckos using a hand-held torch and small binoculars (Case et al. 1994, Keim 2002, Newbery et al. 2005). Each site was surveyed for an average of 15 minutes starting no earlier than 6.30 $\mathrm{pm}$ and finishing no later than $9.00 \mathrm{pm}$. Surveys were not conducted on nights with rain or when the ambient temperature was below $20^{\circ} \mathrm{C}$.

Species identification was confirmed by observation of phenotypic characteristics of each species. For the Asian House Geckos (Figure 1), confirmation was based on the presence of transverse blunt tail tubercles (Wilson and Swan 2003) and detection of one of the three characteristic vocalisations of the species (Greer 1989), the most common and easily identifiable being the 'chuck, chuck, chuck' call. As the Dubious Dtella (Figure 2) bears some resemblance to the Asian House Gecko in size and colouring (B. Newbery, pers. obs.), visual confirmation was based on the lack of the blunt transverse tubercules present on the original and on the base of regenerated Asian House Gecko tails (Wilson and Swan 2003), a cutaneous fold often present on the rear edge of the hind limb (Cogger 1992) and the presence of a pale 'V' shaped marking at the top of the spine or nape of the neck. The identification of the Robust Velvet Gecko (Figure 3) was much less difficult: it is significantly larger and clearly robust in build, has dark brown to black longitudinal markings, small cluster of postanal tubercles and relatively long wide tail (Wilson and Swan 2003).

\section{Habitat characteristics}

Two key habitat characteristics were categorised at each site as follows.

Vegetation density The density of garden or bushland vegetation was subjectively assessed and given a value between 1 and 5, 1 being the lowest level (typically represented by sites covered fully by concrete or grass with no trees and minimal smaller plants), and 5 being the maximum level (typically represented by dense native or introduced foliage comprised of more trees and shrubs than open space); 2, 3, and 4 represented incremental differences between these two extremes. 


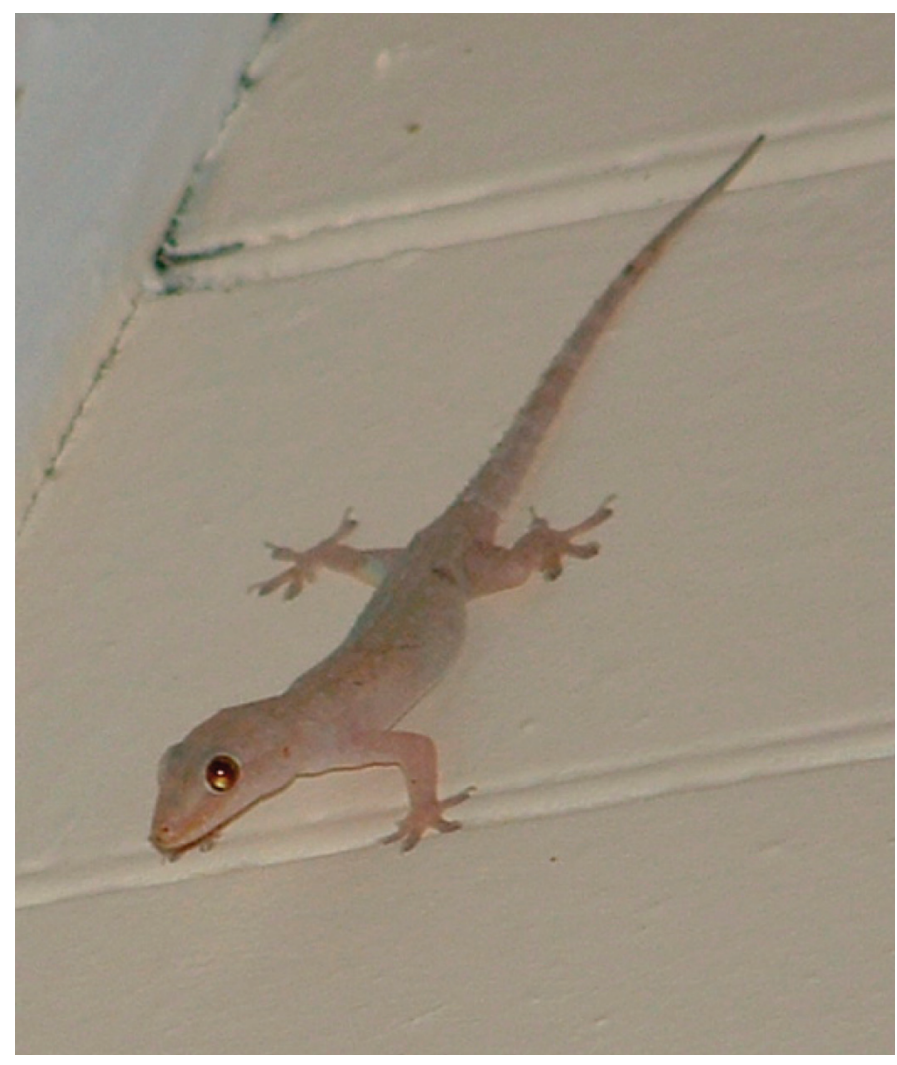

Figure I. The Asian House Gecko can be white to very dark brown and vary from no distinguishing patterns, to mottled with light and dark flecks. A notable characteristic is the severely reduced digit present in the 3-4 position of the front foot and in the 4-5 position of the hind foot; this digit also lacks the deep cleft that divides the broad subdigital lamellae of all the other digits (Greer 1989, Wilson and Swan 2003). This species is well-known for its calls, the most common being the multiple chirp call, or 'chuck chuck chuck' (Marcellini 1977). (Photograph by Brock Newbery)

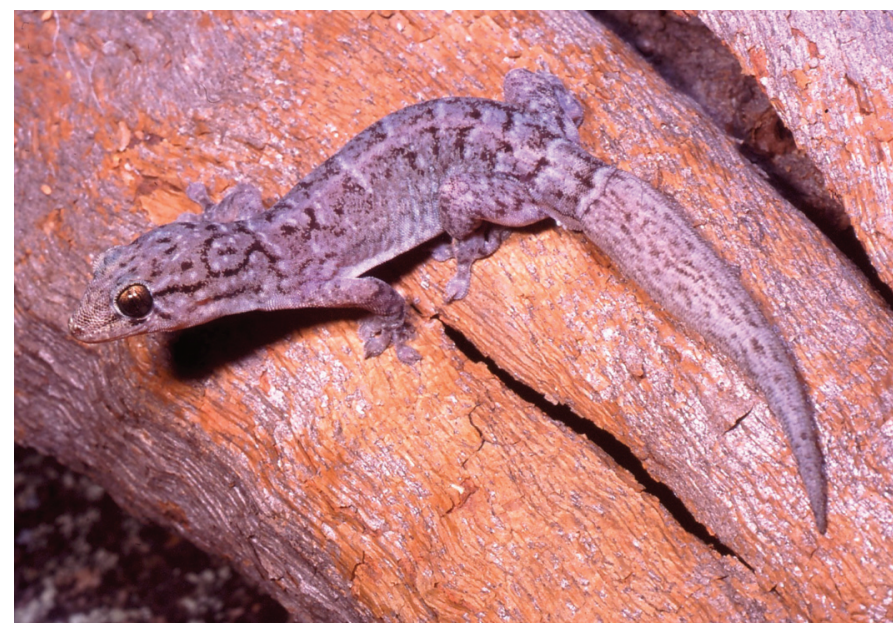

Figure 2. The Dubious Dtella is often similar in size and build to the Asian House Gecko in size and colouring but lacks the blunt transverse tubercules present on the original and on the base of regenerated Asian House Gecko tails (Wilson and Swan 2003). (Photograph by Steve Wilson)

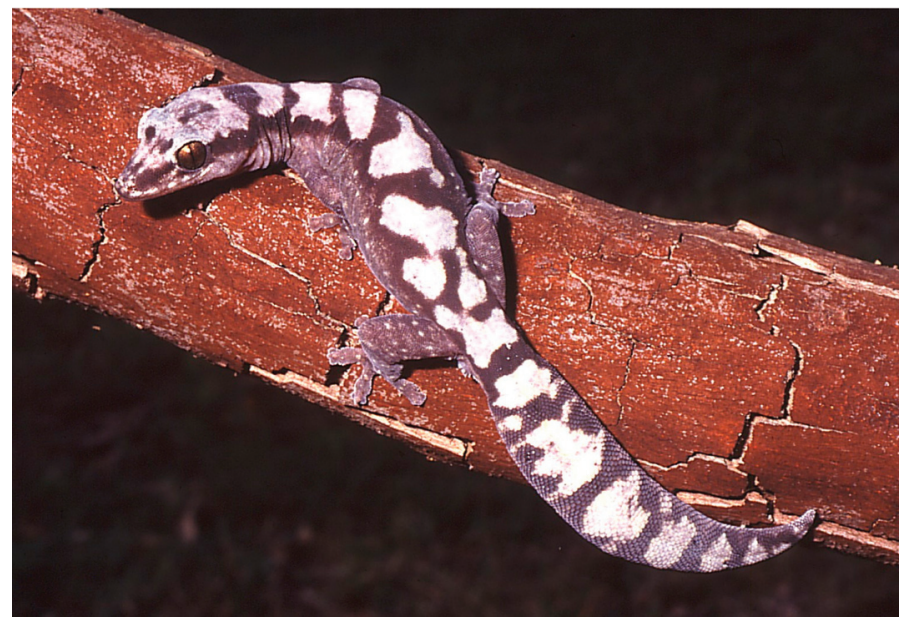

Figure 3. The Robust Velvet Gecko is significantly larger and more robust in build than the Asian House Gecko and has a relatively long and broader tail. Note the dark brown to black longitudinal markings and small cluster of postanal tubercles (Wilson and Swan 2003). (Photograph by Steve Wilson).

External light level As demonstrated by Case et al. (1994), artificial light levels can influence gecko abundance. Therefore, the extent of external light sources within the site (external walls, eves, verandahs, yard) was given a subjective value of $0-5$ with 0 being the lowest level of light (represented by no external lights and no light projected onto the external structure by internal light sources) and 5 being the maximum level of light (represented by five or external sources of light and a high degree of light projected onto the external structure by internal light sources); 1, 2, 3 and 4 comprised incremental differences between these two extremes.

\section{Asian House Gecko stomach contents}

Forty Asian House Gecko specimens, collected independently by the Queensland Museum's Department of Vertebrate Taxonomy from urban and suburban homes in Brisbane and preserved in 80\% ethanol, were examined to determine general dietary intact. The stomach of each specimen was opened using a scalpel and the contents scraped out, taking care to remove only food particles and no stomach lining. The content of each stomach was assessed for an indirect square volumetric value (Balcombe 1994) representing separate taxa, to the level of Order. The content was then rearranged to represent the number of individuals present, according to an approximate number of body parts and volume needed to represent an individual of that Order, or via a direct count of whole individuals. Counts of Orders and indirect square volumetric values were recorded for sites and averages calculated for the categories urban and suburban. The sex, date and location of collection for each preserved gecko specimen were also retrieved from the Museum's database.

\section{Data analysis}

Due to low numbers of both species of native gecko found on sites, their counts were combined for certain analyses. As gecko numbers were not normally distributed (KolmogorovSmironov test, Asian House Geckos $\mathrm{F}_{4,64}=3.01, \mathrm{p}=$ 
$<0.001$, native geckos $\mathrm{F}_{4,64}=3.01, \mathrm{p}=<0.001$ ) and transformation failed to rectify this, non-parametric one-way analysis of variance (Kruskal-Wallis) were used to explore differences in median number of geckos on anthropogenic structures (predominantly residential dwellings) across the habitat types of urban gradient. Analysis was undertaken using SPSS v 11.0 (SPSS 2001). Specific differences between these habitats were further explored using nonparametric multiple comparisons (Zar 1999). Relationships between gecko numbers and environmental variables were explored using Spearman Rank correlations, again in SPSS, with the default line of best fit used.

Differences in invertebrate assemblage summary data (richness, diversity and evenness) from preserved Asian House Gecko stomach contents between the categories of urban and suburban were explored using univariate statistics. Normality of data was explored using one sample Kolmogorov-Smironov Z tests. When normality was achieved for all data, one-way ANOVA was performed to investigate data for significant differences. These two functions were performed using the statistical package SPSS v11 (SPSS 2001). Multiple comparisons between samples with significant differences were undertaken using a Tukey's Test (Zar 1999).

\section{Results}

\section{Densities and distribution across an urban gradient}

Asian House Geckos were found to be present at $72 \%$ of sites while native geckos were found at only $13 \%$ of sites. Along the urban-bushland gradient, Asian House Geckos were found at $95 \%$ of urban sites, $95 \%$ of suburban sites, $40 \%$ of rural sites, but were absent in all bushland sites. In contrast, native house geckos were absent from all urban and suburban sites, but were present at $45 \%$ of rural sites, and $80 \%$ of bushland sites.

There were significant differences in the mean numbers of Asian House Geckos (Kruskal-Wallis $\chi_{3}^{2}=32.98$, $\mathrm{p}<0.001$ ) detected along the urban gradient with urban sites supporting higher numbers than both rural sites (non-parametric pairwise multiple comparisons: $Q=$ 5.9, $\mathrm{p}<0.001)$ and bushland sites $(\mathrm{Q}=3.44, \mathrm{p}<0.005)$. Similarly, suburban sites had significantly more Asian House Geckos than rural $(\mathrm{Q}=4.54, \mathrm{p}<0.001)$ and bushland sites $(\mathrm{Q}=3.81, \mathrm{p}<0.001)$ (Figure 4).

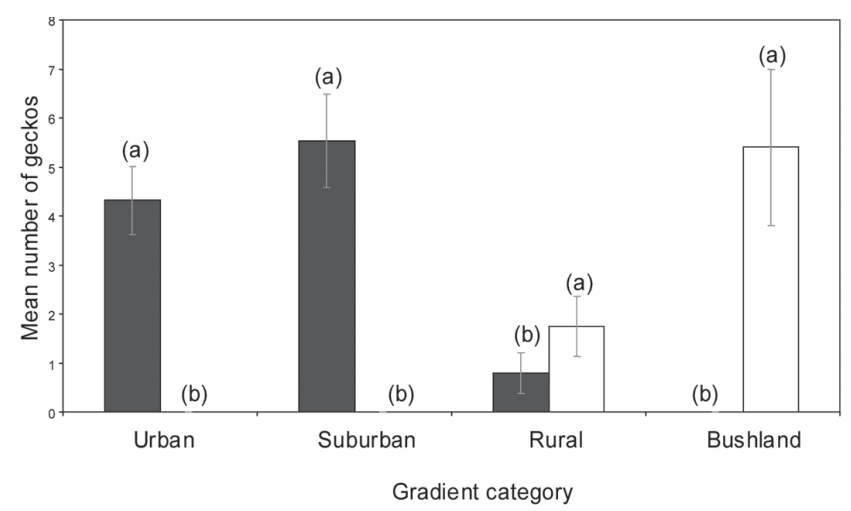

Figure 4. Mean numbers ( \pm SE) of Asian House Geckos (solid) and native house geckos (open) for habitat categories (significant differences indicated by different letters).
There were also significant differences in the mean numbers of native house geckos detected at rural and bushland sites (Kruskal-Wallis $X_{3}^{2}=29.771, p<0.001$ ) with numbers in rural sites being about a third of the means for bushland (Figure 1). Significantly, it was only in rural sites that the two native gecko species were found to be cohabitating with Asian House Geckos. Of the 20 rural sites surveyed, 13 were occupied by geckos. Of these, five sites had two species of gecko coexisting, either Asian House Geckos and Robust Velvet Geckos (three sites), or Asian House Geckos and Dubious Dtellas (two sites). The two native species were also found alone on two additional sites each but never together; a further four rural sites contained only Asian House Geckos. There were no statistical differences in the mean numbers of geckos of any species for rural sites.

Differences in the numbers of the Asian House Gecko and native house geckos were compared for five vegetation levels. These vegetation levels were only slightly correlated to the gradient categories (Spearman's $\rho=0.234, p>$ $0.05)$. There was no significant correlation between the numbers of the invasive species with the vegetation levels. However, native geckos appeared to respond positively to vegetation level (Spearman's $\rho=0.353, p<0.01$ ) with the numbers of these species increasing with greater amounts of vegetation (Figure 5).

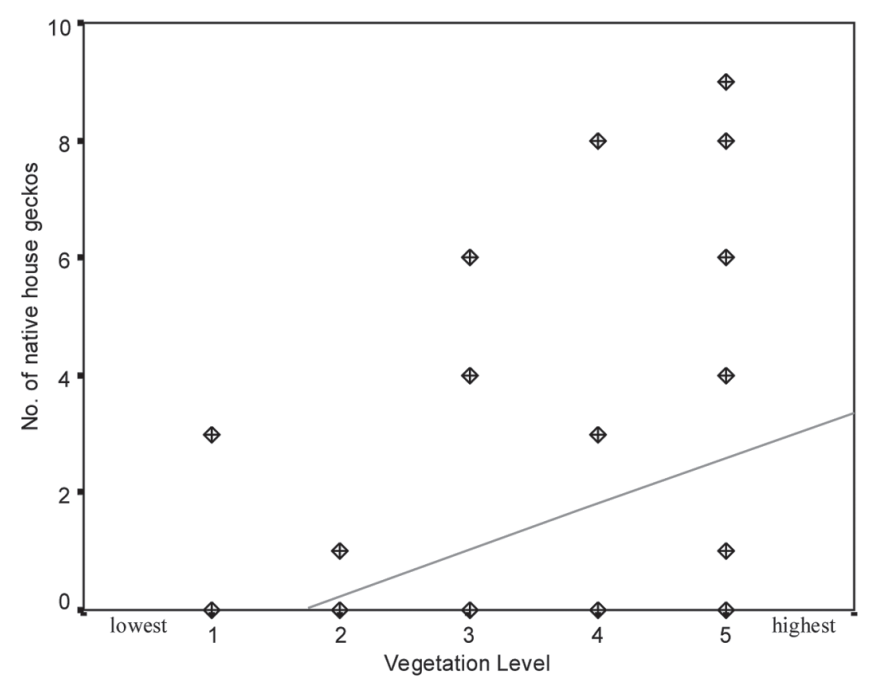

Figure 5. Relationship between the number of native house geckos detected and levels of vegetation, with line of best fit.

External light levels were significantly negatively correlated (Spearman's $\rho=-0.319, \mathrm{p}<0.01$ ) with urban gradient categories, showing a decrease in light levels from urban to rural categories. The number of Asian House Geckos found on sites showed a significant positive correlation (Spearman's $\rho=0.355, \mathrm{p}<0.01$ ) with light level (Figure 6), demonstrating that as the external light levels of a site increased, the number of Asian House Geckos detected also increased. Conversely, the number of native house geckos found on sites showed a significant negative correlation (Spearman's $\rho=-0.299, \mathrm{p}<0.05$ ) with levels of external light. 


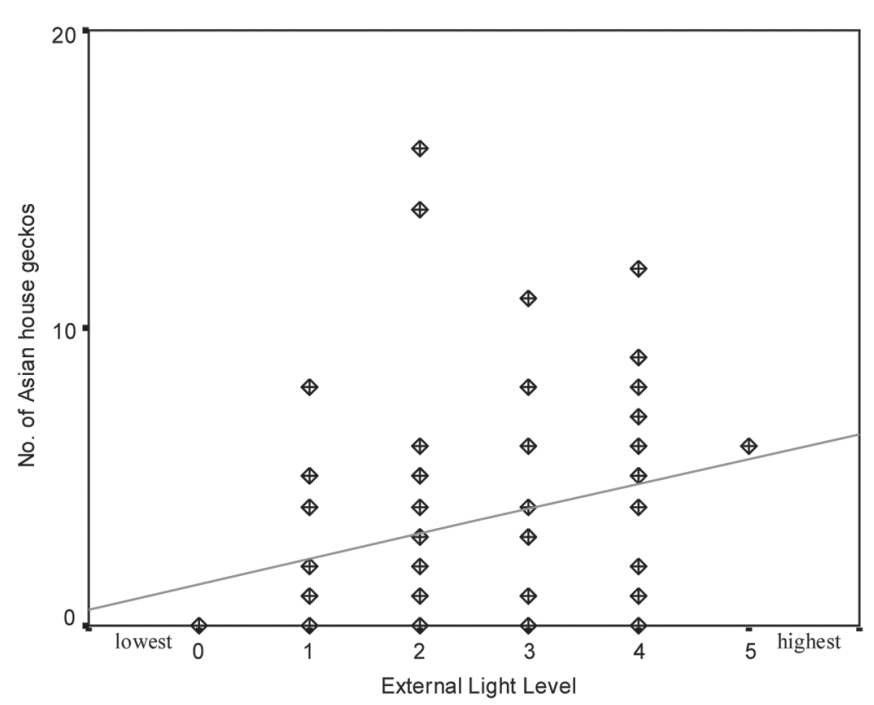

Figure 6. Relationship between the number of Asian House Geckos detected at differing external light levels, with line of best fit.

\section{Stomach contents}

Ten different food types were identified from all Asian House Gecko stomachs sampled $(n=40)$. Of these, three were removed from further analysis due to lack of replication or being non-digestible items (Lepidoptera larvae $(\mathrm{n}=1)$, Coleoptera larvae $(\mathrm{n}=3)$, and rock $(\mathrm{n}=2))$, leaving the following seven Orders: Blattodea, Hymenoptera, Homoptera, Lepidoptera, Diptera, Coleoptera and Araneae. No significant differences were found for Orders between stomachs; each Order had statistically similar proportions in each stomach. There were also no significant differences within the urban and suburban sites. A comparison of means within Orders, however, revealed a significant difference $\left(\mathrm{F}_{10,72}=5.09\right.$, $\mathrm{p}<0.001$ ) with Diptera being significantly greater in proportion than all other Orders (Figure 7).

\section{Discussion}

The present study has extended the limited observation of earlier investigations (Keim 2002, Newbery et al. 2005) that Asian House Geckos occur extensively and continuously throughout urban and suburban areas of Brisbane. The study also confirmed that, at the present time the species in the Brisbane region remains confined to anthropogenic structures and does not appear to have moved into the surrounding bushland. Significantly, we also documented the presence of two species of native house-dwelling geckos on structures in rural and bushland sites, in some cases in apparent coexistence with Asian House Geckos. Finally, we demonstrated that a substantial proportion of the diet of Asian House Geckos consisted of invertebrates attracted to artificial light sources and ingested on anthropogenic structures.

While the numbers of Asian House Geckos detected were highest in urban and suburban house structures, the presence of the species declined significantly in the rural fringe areas of Brisbane and they were completely absent from the bushland areas surveyed. This decline correlated generally with the level of external light, Asian House Geckos numbers decreasing along with the level of light. External light levels are also negatively correlated with the gradient paradigm, with rural areas being significantly darker than urban and suburban; bushland areas generally had no light sources. Invertebrate diversity and abundance, however, was not negatively correlated to the three parts of the urban gradient assessed, suggesting that it was not a lack of food resources per se that restricted the numbers of

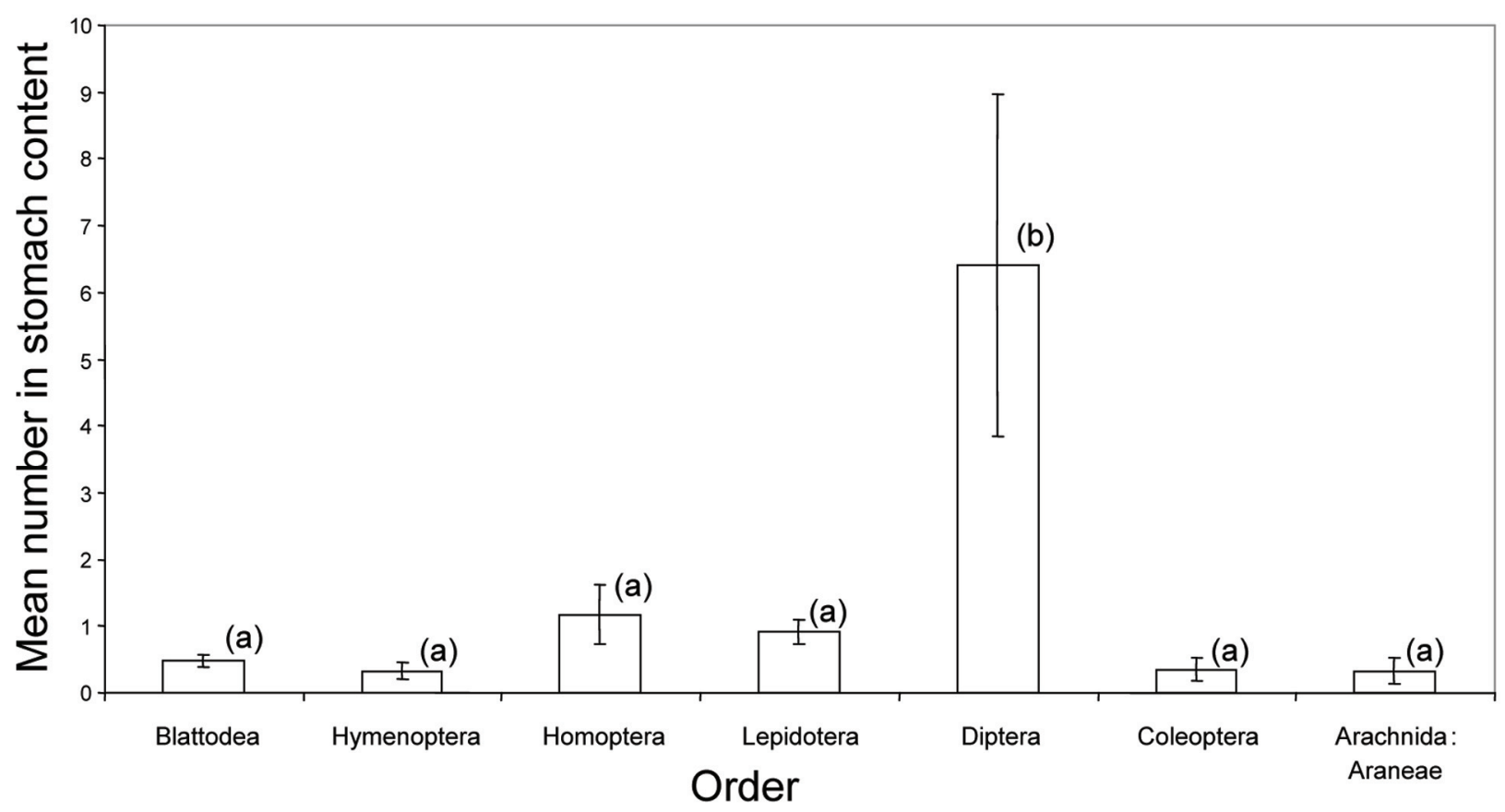

Figure 7. Mean number of each Order present in stomach content of Asian house geckos across all samples $(n=40)$ (bars with different letters were significantly different). 
Asian House Geckos, but more likely the lack of spatiallyclumped foraging resources typically present around light sources. In addition, the lack of structurally simple foraging surfaces in bushland sites potentially deprived the species of its typical anthropogenic feeding areas.

Native house-dwelling geckos were absent from all urban and suburban sites surveyed, although it is known that Robust Velvet Geckos do occur at low densities on suburban buildings directly adjacent to bushland reserves (B. Newbery pers. obs.). We did find native house geckos on structures in $45 \%$ of rural sites and $80 \%$ of bushland sites. Of the 20 rural sites surveyed, Asian House Geckos occupied the same number of sites as the two native species, although Asian House Geckos occurred on nine sites while the native species were detected on only four or five sites each, and never together. The finding that numerous rural sites supported both Asian House Geckos and a species of native house gecko appears to demonstrate, superficially, the native species' capacity to forage on shared resources with the invasive species in rural areas.

Elsewhere, the Asian House Gecko has been shown to exert at least two forms of interference competition on other house-dwelling geckos. The first of these is interspecific territoriality and juvenile predation, which has been observed between the invasive species and at least two other gecko species (Petren et al. 1993, Cole et al. 2005). However, Case's et al. (1994) examination of Asian House Gecko stomach contents, as well our own, found no evidence of predation on other vertebrates. The second form of competition is that of behavioural dominance, which has been demonstrated between Asian House Geckos and other smaller species (Petren et al. 1993). In dominance relationships in most reptiles, two generalised rules appear to be universal: body size and physical dominance are generally correlated; and the males of a species are usually more aggressive than females (Case et al. 1994). In Brisbane, the Robust Velvet Gecko is significantly larger than the Asian House Gecko $(\sim 80 \mathrm{~mm}$ vs $\sim 65 \mathrm{~mm}$ snout-vent length; Cogger 1992) and, where it is present in rural sites, is generally in higher numbers than the invasive species. These observations support the suggestion (P. Couper, pers. com. cited in Keim 2002) that adult Robust Velvet Geckos are potentially capable of predating on the comparatively smaller juveniles of the Asian House Gecko. Similarly, the larger size of the native species should provide a significant advantage in malemale interactions between the species.

For these reasons, the intermediate-sized Dubious Dtella ( $\sim 70 \mathrm{~mm}$ SVL; Cogger 1992) is of greater potential risk of being displaced in anthropogenic habitats by the Asian House Gecko. Moreover, the species is usually found only in male and female pairs, resulting in naturally low densities (Bustard 1969, cited in: Greer 1989: 69). This would infer a numerical advantage of Asian House Geckos over the Dubious Dtella in situations of coexistence, especially when the invasive species has a higher potential to reach greater numbers. This has been suggested as one of the causative mechanisms in the competitive displacement of the asexual Mourning Gecko which, due to its smaller body size and lack of aggressivelydominant males, is agonistically displaced from spatially clumped food resources (Case et al. 1994).

The Asian House Geckos capacity for highly effective foraging on structurally simple surfaces is demonstrated by the findings that, on average, one individual contained approximately $10 \%$ of the total volume of invertebrate mass attracted to an artificial light source over the course of one night (B. Newbury, unpublished data). Clearly, Asian House Geckos are highly efficient insectivores, especially of mosquitoes. This, along with a widespread (though unconfirmed) perception that these geckos eradicate most house-dwelling cockroaches (D. Jones unpublished data), may be partially responsible for the generally positive attitude among most suburban residents towards the presence of this invasive species in their homes (Newbery 2005). This positive regard within the community, in stark contrast to that toward most other Australian introduced pests (ABC 2004), is another significant element in what is an increasingly complex ecological story of an invasive animal adapting to urban Australia.

\section{Acknowledgements}

This study could not have been completed without the assistance, advice and cooperation of many people. We thank Fran Sheldon, Terry Reis, Steve Balcombe, Jessica Worthington-Wilmer, Patrick Couper, Andrew
Amey, Roger Kitching and David Booth for their various contributions of advice and assistance. Thanks are also extended for all the residents who allowed us access to their properties at odd hours of the evening.

\section{References}

ABC 2004. ABC WildWatch: The quest for pests. www.abc.net.au/wildwatch/results.htm.

Balcombe, S. R. 1994. The role of interspecific competition in regulating the fish assemblages of Baddaginnie creek. Honours dissertation, La Trobe University, Victoria.

Brown, S., Lebrun, R., Yamasaki, J. and Ishii-Thoene, D. 2002. Indirect competition between a resident unisexual and an invading bisexual gecko. Behaviour 139: 1161-1173.

Bustard, H. R. 1970. Activity cycle of the tropical house gecko Hemidactylus frenatus. Copeia 1: 173-176.

Case, T.J., Bolger, T. and Petren, K. 1994. Invasions and competitive displacement among house geckos in the tropical Pacific. Ecology 75: 464-477.

Cogger, H. G. 1992. Reptiles and Amphibians of Australia. Reed Books, Chatswood, NSW.

Cole, N. C., Jones, C. G. and Harris S. 2005. The need for enemy-free space: The impact of an invasive gecko on island endemics. Biological Conservation 125: 467-474.

Covacevich, J. 2001. Herpetological 'foreigners' on Norfolk Island, an external territory of Australia. Memoirs of the Qld Museum 46: 408. 
Greer, A. E. 1989. The Biology and Evolution of Australian Lizards. Surrey Beatty \& Sons Pty Limited, Chipping Norton, NSW.

Greer, A. E. 2004. Encyclopedia of Australian Reptiles Gekkonidae. Australian Museum Online.

Hanley, K. A., Petren, K. and Case T. J. 1998. An experimental investigation of the competitive displacement of a native gecko by an invading gecko: no role for parasites. Oecologia 115: 196205.

Keim, L. D. 2002. Spatial distribution of the introduced Asian House Gecko across suburban/forest edges. Honours dissertation, University of Queensland., Brisbane.

Marcellini, D. L. 1977. The function of vocal display of the lizards Hemidactylus frenatus (Sauria: Gekkonidae). Animal Behaviour 25: 414-417.

McDonnell, M. J., and Pickett, S. T. A. 1990. Ecosystem structure and function along urban-rural gradients: an unexploited opportunity for ecology. Ecology 71: 1232-1237.

Meshaka, W. E. J., Butterfield, B. P. and Hauge, B.. 1994. Hemidactylus frenatus established on the Lower Florida Keys. Herpetological Review 25.

Murphy-Walker, S. and Haley, S. R. 1996. Functional sperm storage duration in female Hemidactylus frenatus (Family Gekkonidae). Herpetologica 52: 365-373.

Newbery, B. S., Dawson, P. and Jones, D. N. 2005. Density of Asian House Geckos Hemidactylus frenatus within suburban Brisbane. The Queensland Naturalist 43: 8-13.

Pernetta, J. C., and Black, D. 1983. Species of gecko (Lepidodactylus) in the Port Morseby area, with the description of a new species. Journal of Herpetology 17: 121-128.
Petren, K., Bolger, D., and Case, T. J. 1993. Mechanisms in the competitive success of an invading sexual gecko over an asexual native. Science 259: 354-358.

Petren, K., and Case, T. J. 1996. An experimental demonstration of exploitation competition in an ongoing invasion. Ecology 77: 118-132.

Petren, K., and Case, T. J. 1998. Habitat structure determines competition intensity and invasion success in gecko lizards. Proceedings of the National Academy of Science 95: 11739-11744.

Pianka, E. R., and Sweet S. S. 2005. Integrative biology of sticky feet in geckos. BioEssays 27: 647-652.

Russell, A. P. 2002. Integrative Functional Morphology of the Gekkotan Adhesive System (Reptilia: Gekkota). Integrative Comparative Biology 42: 1154-1163.

SPSS. 2001. SPSS v11.0. SPSS Inc., Chicago. Il.

Swanson, S. 1990. Lizards of Australia. Angus \& Robertson, North Ryde.

Vences, M., Wanke, S. D., Vieites, Branch, W., Glaw F., and Meyer, A. 2004. Natural colonization or introduction? Phylogeographical relationships and morphological differentiation of house geckos (Hemidactylus) from Madagascar. Biological Journal of the Linnean Society 83: 115-130.

Wilson, S., and Swan, G. 2003. A Complete Guide to Reptiles of Australia. New Holland Publishers, Frenchs Forest, NSW.

Worthington-Wilmer, J., P. Couper, and A. Amey. 2003. A preliminary investigation of genetic diversity in the invasive asian house gecko (Hemidactylus frenatus). Pages 17 in Australian Society of Herpetologists, Mary River Park, NT, Australia.

Zar, J. H. 1999. Biostatistical Analysis. Prentice Hall, New Jersey. 